\title{
O espaço e o tempo da desinstitucionalização
}

\section{VENTURINI, Ernesto.}

\section{A linha curva: o espaço e o tempo da desinstitucionalização}

Rio de Janeiro: Editora Fiocruz, 2016

\section{| ${ }^{1}$ Milene Santiago Nascimento |}

1 Bolsista CAPES (Doutorado), Programa de Pós-Graduação em Saúde Coletiva, Instituto de Medicina Social, Universidade do Estado do Rio de Janeiro. Rio de Janeiro-RJ, Brasil (milenesantiago@hotmail.com). ORCID: 0000-0002-5132-1723

\section{Recebido em: 21/12/2018}

Aprovado em: 07/01/2019

Revisado em: 12/10/2019

DOI: http://dx.doi.org/10.1590/S0103-73312019290417

A linha curva: o espaço e o tempo da desinstitucionalização reúne textos de Ernesto Venturini, transmitindo suas experiências, reflexóes e construções teóricas sobre a reforma psiquiátrica italiana. $\mathrm{O}$ autor destaca a polissemia do termo desinstitucionalização e, ao mesmo tempo, convida o leitor a "redescobrir seu significado original" (VENTURINI, 2016, p. 72).

São três justificativas que fundamentam o livro: observação de equívocos em processos atuais de desinstitucionalização, que sofrem influência de políticas neoliberais; constatação de que os princípios fundamentais da desinstitucionalização são negados ou desvirtuados; existência de uma ambiguidade do termo, que indica um simples processo de desospitalização ou transinstitucionalização, e, por outro lado, uma transformação do paradigma da psiquiatria. Seu referencial teórico principal é a obra de Franco Basaglia.

As questóes trazidas ao longo das 194 páginas do livro seguem as seguintes coordenadas: 1) a prática e a dialética do poder; 2) o protagonismo da subjetividade; 3) o espaço e o tempo da desinstitucionalização. Essas coordenadas são divididas em cinco capítulos.

O primeiro capítulo, intitulado "A prática", traz cinco artigos que descrevem a experiência do autor na reforma psiquiátrica italiana em Imola, Gorizia e Trieste. 
Critica o campo da psiquiatria, que cinde teoria e prática, além de produzir cronicidade. Destaca-se por situar a desinstitucionalização como um campo da prática, fundamentada num processo de desconstrução da cronicidade. Para o autor, esse processo é um ato terapêutico, cujo alicerce é o exercício de direitos, a reciprocidade, a cooperaçáo social e o protagonismo dos pacientes e familiares.

"Dialética do poder" é o título do capítulo 2, composto por três artigos que analisam as práticas de desinstitucionalização, indicando que existe uma verdadeira e uma falsa desinstitucionalização. A primeira seria, de fato, a ruptura com a lógica da psiquiatria tradicional, e a segunda, que repropóe e camufla essa psiquiatria. É justamente essa ambiguidade que sustenta o ponto central do livro, nas palavras do autor, "desinstitucionalizar a desinstitucionalizaçáo" (VENTURINI, 2016, p. 72). Venturini propóe que o uso do termo seja suspenso, para que se possa chegar às suas raízes. Essa reflexão traz a originalidade do pensamento do autor, que sugere quatro fases em progressão da desinstitucionalização: desospitalização, habilitação psicossocial, inclusão social e promoção de valor social. Essas fases são divididas em dois grupos descontínuos: desospitalização e desinstitucionalização.

O capítulo 3, "Protagonismo da subjetividade", é composto por dois artigos, nos quais Venturini ressalta que a desinstitucionalização é mais do que uma mudança no cuidado e de novas formas terapêuticas: ela se produz na comunidade. A reabilitação é deslocada para a cidade, tendo como palavras-chave a subjetividade, as relaçôes, a igualdade, a individualidade, a solidariedade e a diversidade. Com essa concepção, Venturini sobressai-se por retirar a desinstitucionalização de uma lógica de inclusão social. Para ele, inclusão remete à normalização. Ainda neste capítulo, o autor chama a atenção para os riscos da "falsa" desinstitucionalização, ou seja, enfraquecimento do movimento antimanicomial, por influência de um contexto político, social e econômico desfavorável; a "psiquiatria reformada", no lugar da desinstitucionalização; a perda da voz dos usuários; o risco de novas formas de assistência tomarem lugar dos pilares da desinstitucionalizaçáo; e a falta de coerência comportamental dos profissionais com os princípios da desinstitucionalização. Todas essas situaçôes contribuiriam para a construção de novas figuras no lugar do louco.

No capítulo 4, intitulado "O espaço da desinstitucionalização", através de sete artigos, o autor reflete sobre a dimensão espacial do que denomina "lugares liberados", espaços habitados ou frequentados pelos sujeitos desinstitucionalizados. Habitar e frequentar espaços sociais pressupóem solidariedade e reciprocidade nas 
relaçôes. Nesse sentido, o ponto principal e original do capítulo são as críticas do autor às ideias que relacionam desinstitucionalização a integração social e reabilitação, fazendo ressalvas aos modelos terapêuticos. Para ele, a desinstitucionalização apenas é possível na cidade, em rede. É o que Venturini denomina de função reabilitadora da cidade. Traz, com essa noção, uma importante elaboração: o capital social como instrumento de construçáo da rede. Assim, o autor propóe que o objetivo da desinstitucionalização é mudança; seu instrumento é conflito; o papel dos profissionais é serem agentes culturais das contradiçóes. Venturini sugere que intercâmbio e reciprocidade substituam integração e reabilitação.

Composto por três artigos, o quinto capítulo intitula-se "O tempo da desinstitucionalização". Trata-se da introdução da dimensão temporal, que comporta um tempo cronológico e simbólico, operada pela desinstitucionalização. No lugar da criticada reabilitação, Venturini sugere a habilitação, trazendo um diferencial para pensarmos a desinstitucionalização. Habilitação se refere ao presente, à parte saudável, ao exercício de direitos, às trocas interpessoais e sociais e à cooperação (pilares da desinstitucionalização). Sob todos esses aspectos, o autor nos dirige para um retorno aos princípios da desinstitucionalização.

A obra se destaca por três pontos: uma concepção de desinstitucionalização, que rompe com a ideia de mudança no paradigma de clínica e cuidado; a abordagem da concepção de cronicidade; e a polissemia do termo desinstitucionalização. Venturini não nega a importância de estratégias terapêuticas e do cuidado voltado à pessoa com sofrimento mental. Entretanto, neste livro, ele deixa claro que a desinstitucionalização não se refere à clínica. Para o autor, o "terapêutico" da desinstitucionalização é o laço social, que se constrói através da reciprocidade, solidariedade e contratualidade social. Assim, ele redefine o papel do profissional, deslocando-o do lugar de "terapeuta" para o papel de mediador cultural. Nesse sentido, os recursos da comunidade são, em si, terapêuticos, levando Venturini a afirmar a cidade como "sistema imunitário" (VENTURINI, 2016, p. 149).

Para o autor, as propostas de reabilitação e integração social se traduzem em um erro ideológico, pois pressupóem recuperação, ou uma modalidade de adaptação de um estranho a uma realidade dominante. Deve-se chamar a atenção para essas críticas, uma vez que, com elas, Venturini desconstrói a própria clínica. Em diversas passagens do livro, o autor tece ressalvas às propostas terapêuticas antimanicomiais. Ele se apresenta preocupado com as deturpaçóes com relação ao que chama de 
"verdadeira desinstitucionalização". Um processo que se sustente apenas numa preocupaçáo em reorientar a clínica para um modo mais humanizado, ou na implantação de serviços, corre o risco de não efetivar a desinstitucionalização.

Portanto, a desinstitucionalização como processo filosófico incide no tecido social, não se tratando de uma mudança de paradigma clínico. Traz, nesse sentido, uma originalidade ao utilizar-se da noçáo de capital social como o instrumento de intervenção na rede social. Seu uso na desinstitucionalização está nas ideias de responsabilidade e protagonismo dos sujeitos e familiares, na capacidade de utilizar os recursos econômicos e da comunidade, e na inserção de novos atores além do corpo técnico.

A análise de Venturini sobre a cronicidade atravessa o livro. Ela se coloca justamente nas críticas do autor sobre algumas práticas contemporâneas. O estudioso ainda afirma a existência de uma cronicidade presente nessas açôes e nos serviços, gerada pela deturpação da proposta original da desinstitucionalização. Essa deturpação pode ser causada por alguns fatores: pelas influências do neoliberalismo; pela não superação da lógica de internação, sustentada pelo investimento de recursos financeiros nos hospitais e outros locais de internação; pela criação de "novas formas de assistência” e pela falta de coerência comportamental dos profissionais, que parecem sucumbir à lógica de alienação no social.

O título do livro faz alusão ao pensamento de Oscar Niemeyer, considerando a desinstitucionalizaçáo uma linha curva: em seu calor, tempo dilatado, leveza, imprevisibilidade, opóe-se à rigidez do pensamento manicomial, com seus ângulos e agudezas. Inclusive, Venturini parte da cronicidade como mola propulsora em sua experiência de desinstitucionalizaçáo, ao mesmo tempo chega a uma desinstitucionalizaçáo que pode ser produtora de cronicidade, como um raciocínio circular.

Cabe ressaltar que, dos sentidos que constrangem a experiência da loucura descritos por Rotelli, Leonardis e Mauri (2001), que são cronicidade, periculosidade, inimputabilidadee incapacidade, Venturini se deteve na cronicidade, não abordando os demais. Entretanto, quando concebe os níveis da desinstitucionalização, que são habilitação psicossocial, inclusão social e promoção social, e, sobretudo esta última, parece estar aludindo à periculosidade, inimputabilidade e incapacidade. A promoção de valores sociais atua sobre a representação mental e cultural de uma 
comunidade a respeito da loucura. Nesse sentido, se desconstroem os significados de perigoso, incapaz e irresponsável do louco.

Venturini traz um diferencial importantíssimo acerca da concepção de desinstitucionalização: as formas e os sentidos de desinstitucionalização. Através dessa concepção, podemos inferir a polissemia do termo. Os níveis da desinstitucionalização, acima indicados, são desdobramentos da análise de dois modelos principais: a desospitalização e a desinstitucionalização. Existe, entre eles, uma descontinuidade, fazendo com que Venturini escolha dividi-los em quatro modelos ou níveis: desospitalização, habilitação psicossocial (primeiro nível, processo de aceleração de alta e intervençôes na organização sociossanitária); inclusão social (segundo nível, que atua sobre as instituiçôes e modifica o circuito psiquiátrico); e por último, a promoção de valor social (terceiro nível, que corresponderia à verdadeira desinstitucionalização). Para Venturini, esses modelos, ou formas de desinstitucionalização resultam em diferentes sentidos que podem ser atribuídos a ela, como "integração social", "reabilitação social”, "cuidado ampliado", entre outros.

Já foram realizadas resenhas dessa obra (GULJOR, 2017; RAMOS, 2017). Guljor ressaltou que o autor se detém no cuidado cotidiano das pessoas em sofrimento, articulando-o com a macro-política. Já Ramos destacou que a polissemia se encontra na própria definição do conceito de desinstitucionalização. Considerando a análise que Venturini faz do contexto social contemporâneo fortemente influenciado pelo neoliberalismo, o autor nos presenteia com argumentos para pensarmos o contexto da Saúde Mental no Brasil.

A redução de investimento nas políticas sociais e de saúde, o deslocamento de pessoas pelo território, as exigências de açôes eficazes em curto prazo e máximo desempenho dos profissionais e a própria característica geográfica e urbana das cidades tornam o espaço social pouco acolhedor para o diferente. Situa-se aí a loucura, que possui o significado de estrangeiro, assim como o portador de necessidades especiais, crianças, jovens, idosos, imigrantes. Nesse hiato surgem discursos de normalização, conservadorismo e moralidade. Para Venturini, estes são fortes obstáculos à desinstitucionalização.

Em 2018, a Comissão Lancet sobre Saúde Mental Global e Desenvolvimento Sustentável lançou um relatório de avaliação acerca da implantação da agenda global de saúde mental no contexto dos Objetivos do Desenvolvimento Sustentável (ODS). A agenda foi construída há dez anos, priorizando a ampliação de serviços 
de saúde mental para pessoas de baixa e média renda e para países de baixa renda, cujas conquistas dos direitos humanos ao cuidado e à dignidade foram afetadas. $\mathrm{O}$ relatório afirma que o mundo vive uma crise no que diz respeito à saúde mental. Foram verificados: lentidão nos avanços de açôes para prevenção e tratamento dos transtornos mentais, bem como para a promoção de saúde mental; aumento de doenças mentais, causado por transiçôes demográficas, ambientais e sociopolíticas; manutenção de pessoas institucionalizadas em hospitais e prisōes e pessoas em situação de rua com seus direitos violados e sem proteção legal; pouco investimento financeiro por parte dos governos nos serviços de saúde mental; e, embora os serviços de saúde mental em muitos países tenham sido pioneiros em produzir cuidados modernos mais rápidos e amplos do que os de saúde física, os de saúde mental possuem qualidade de oferta de cuidado pior do que os serviços de saúde física. $\mathrm{O}$ relatório ainda indica que existe uma falha coletiva para atender essa crise global, que apresenta resultados drásticos, como perdas de capacidade e muito sofrimento que poderia ser evitado (PATEL et al., 2018).

Os resultados desse relatório confirmam muitos dos equívocos relacionados à desinstitucionalização criticados por Venturini, neste caso tendo como consequência uma desassistência. Além disso, o contexto político em que vivemos no Brasil, que ameaça a democracia e os direitos sociais adquiridos, também confirmam os resultados do estudo. A redução de investimentos nas políticas sociais e o aumento da desigualdade social fazem com que os serviços de saúde tenham poucas condiçôes de cuidar de pessoas em sofrimento mental. As condiçóes pioram, haja vista a Portaria no 3.588/2017 (BRASIL, 2017), que integra os hospitais psiquiátricos e ambulatórios especializados na Rede de Atenção Psicossocial. Os hospitais psiquiátricos não haviam sido incluídos na Portaria no 3.088, de 2013 (BRASIL, 2013), que definia a Rede de Atenção Psicossocial. Observa-se um movimento contrário ao proposto pela lógica da desinstitucionalização. Com o golpe de 2016 e consequente processo de desmonte do Sistema Único de Saúde (SUS), os hospitais psiquiátricos tornaram-se parte integrante da Rede, recebendo recursos financeiros. Em nota, a Associação Brasileira de Saúde Coletiva (ABRASCO, dez. 2017) se posicionou contra essa mudança na legislação, afirmando que se trata de um retorno à ênfase em modalidades manicomializadoras de tratamento, o que desfinancia, precariza e reduz os serviços de saúde. A Associação Brasileira de Saúde Mental (ABRASME, 2018), em entrevista para o sítio Viomundo, destacou que as mudanças políticas 
ocorreram sem participação popular, sem consulta aos técnicos, sem esclarecimento dos motivos da mudança, caracterizando-se como um retrocesso ao movimento antimanicomial e uma ameaça à democracia.

O livro de Venturini contribui, assim, para refletirmos sobre o cenário que se apresenta, além de ser valiosa ferramenta para a construção de práticas desinstitucionalizantes, ou seja, leve e com o "tempo dilatado" necessário, evitando assim a "rigidez" manicomial.

\section{Referências}

GULJOR, A. P. Resenha "A linha curva: o espaço e o tempo da desinstitucionalização”. Cad. Saúde Pública, v. 33, n. 12, p. 1-2, 2017.

BRASIL. Gabinete do Ministro de Estado da Saúde. Portaria $n^{\circ} 3.588$, de 21 de dezembro de 2017. Altera as portarias de consolidação no 3 e no 6, de 28 de setembro de 2017, para dispor a Rede de Atenção Psicossocial, e dá outras providências. Brasília, 2017. Disponível em: <http://bvsms. saude.gov.br/bvs/saudelegis/gm/2017/prt3588_22_12_2017.html>. Acesso em: 19 dez. 2018.

.Portaria no 3.088, de 23 de dezembro de 2011. Institui a Rede de Atençáo Psicossocial para pessoas com sofrimento ou transtorno mental e com necessidades decorrentes do uso de crack, álcool e outras drogas, no âmbito do Sistema Único de Saúde. Brasília, 2011. Disponível em: <http://bvsms.saude.gov.br/bvs/saudelegis/gm/2011/prt3088_23_12_2011_rep.html>. Acesso em: 19 dez. 2018.

ABRASCO. Nota contra os retrocessos da CGMAD/MS frente à politica brasileira de saúde mental. Rio de Janeiro, 11 dez. 2017. Disponível em: <https:/www.abrasco.org.br/site/outras-noticias/ notas-oficiais-abrasco/retrocessos-saude-mental-governo-temer/32436/> Acesso em: 19 dez. 2018.

PATEL, V. et al. The Lancet Commission on global mental health and sustainable development. bThe Lancet, v. 392, p. 1553-1598, 2018. Disponível em: < https:/www.thelancet.com/journals/ lancet/article/PIIS0140-6736(18)31612-X/fulltext>. Acesso em: 16 out. 2019.

RAMOS, D. K. R. R.Resenha "A linha curva: o espaço e o tempo da desinstitucionalização". Saúde Debate, v. 41, n. 115,p. 1236-1238, 2017.

ABRASME. Reportagem com Walter Oliveira sobre a "nova" política de saúde mental. Viomundo, 16 fev. 2018. Disponível em: <http://www.abrasme.org.br/informativo/view?ID_ INFORMATIVO=383>Acesso em: 19 dez. 2018.

ROTELLI, F.; LEONARDIS, O.; MAURI, D. Desinstitucionalização, uma outra via. In: NICÁCIO, F. (Org.). Desinstitucionalização. 2.ed. São Paulo: Hucitec, 2001, p. 17-59.

VENTURINI, E. A linha curva: o espaço e o tempo da desinstitucionalização. Rio de Janeiro: Editora FIOCRUZ, 2016. 